\title{
Effects Of Some Alcoholic Beverages on Haematological and Plasma Biochemical Parameters in Male Albino Rats.
}

\author{
Oyedeji K.O ${ }^{1}$. Bolarinwa A.F ${ }^{2}$, Owaduge D.O. ${ }^{1}$ \\ ${ }^{I}$ Department of Physiology, Faculty of Basic Medical Sciences, Ladoke Akintola University of Technology, \\ P.M.B. 4000, Ogbomoso, Nigeria \\ ${ }^{2}$ Department of physiology, College of Medicine, University of Ibadan, Ibadan, Nigeria
}

\begin{abstract}
Summary: The aim of this study was to investigate the effects of some alcoholic beverages (Gulder, Guiness, Chelsea, Rose-Daniel and Bacchus) on haematological and plasma biochemical parameters in male albino rats. Treatment of rats for 42 days with all the alcoholic beverages (except Gulder and Rose-Daniel) caused significant $(p<0.05)$ increase in MCH value, while treatment of rats with Guiness caused significant $(p<0.05)$ decrease and increase in the neutrophil and lymphocyte values respectively relative to their controls. Treatment of rats with all the alcoholic beverages caused no significant $(p>0.05)$ changes in platelet, total WBC and $R B C$ counts and some indices relating to it (Hb, PCV, MCV and MCHC) relative to their controls. Treatment of rats with all the alcoholic beverage caused significant $(p<0.05)$ increase in total protein level relative to the control. Treatment of rats with all the alcoholic beverages (except Rose-Daniel) caused significant $(p<0.05)$ increase in the activity of AST relative to the control, while treatment of rats with all the alcoholic beverages (except Bacchus and Rose-Daniel) caused significant $(p<0.05)$ increase in the activity of ALT relative to the control. These findings indicate that alcoholic beverages could have some deleterious effects on the blood chemistry of male albino rats.

Key Words:Alcoholic beverages, Albino rats, Red blood count, Total white blood count
\end{abstract}

\section{Introduction}

Alcohol is a psychoactive drug that has a depressant effect. An alcoholic beverage is a drink that contains ethanol (commonly called alcohol). Alcoholic beverages are divided into three general classes beers, wines and spirits.

Alcohol has been used medically throughout recorded history; its medicinal properties are mentioned 191 times in the Old and New Testaments (Straus, 1979). It has been shown in epidemiological studies that moderate consumption of alcoholic beverages has a protective effect against the clinical complications of coronary heart disease (De Wood et al., 1980) Drinkers of alcoholic beverages have been reported to have higher risk of developing hypertension (Fuchs et al., 2001). An analysis of pairs of twins (23,000 finish twins) with different drinking patterns found that those who consumed alcohol in moderation had half the risk of developing type 2 (adult-onset) diabetes compared to those who consumed less alcohol (Carlsson et al., 2003). A study in developing Rhesus monkeys has demonstrated detrimental effects of alcohol on the activation of hormone secretion that accompanies female puberty (Dees et al., 2000) Research with adult rats has shown that alcohol increases opiod activity in the brain (Froehlich, 1993). It has also been reported that some of the commonly ingested alcoholic beverages are potent stimuli of gastric acid output (Singer et al., 1987).

However, due to paucity of information from literature on the effects of alcoholic beverages on haematolgical and plasma biochemical parameters in albino rats, these studies therefore aim at investigating the effects of some alcoholic beverages on these aforementioned parameters.

\section{Experimental Animals.}

\section{Materials And Methods}

Adult male albino rats weighing between $160 \mathrm{~g}$ and $180 \mathrm{~g}$ bred in the Animal House of Physiology Department, LAUTECH, Ogbomoso were used. They were housed under standard laboratory conditions with a 12 hours daylight cycle and had free access to feed and water; they were acclimatized to laboratory conditions for two weeks before the commencement of the experiments. All experiments were carried out in compliance with the recommendations of Helsinki's declaration on guiding principles on care and use of animals.

\section{Alcoholic Beverages}

The alcoholic beverages (Gulder, Guiness, Chelse. Rose-Daniel and Bacchus) were bought from LAUTECH mini market. The three groups of alcoholic beverages (wine, beer and spirit) were used in this research work. Rose-Daniel and Bacchus were used in the wine group, Gulder and Guiness were use in the beer group, while Chelsea was used in the spirit group. 


\section{Experimental Design}

Thirty animals were randomly divided into six groups, with each group consisting of five rats. The six groups of rats were subjected to the following oral treatments once a day for six weeks (42 days):

Group I rats received $10 \mathrm{ml} / \mathrm{kg} \mathrm{BW}$ of Bacchus

Group II rats received $10 \mathrm{ml} / \mathrm{kg}$ BW of Chelsea

Group III rats received $10 \mathrm{ml} / \mathrm{kg}$ BW of Guiness

Group IV rats received $10 \mathrm{ml} / \mathrm{kg}$ BW of Gulder

Group V rats received $10 \mathrm{ml} / \mathrm{kg}$ BW of Rose-Daniel

Group VI rats received $0.5 \mathrm{ml}$ of distilled water as the control group.

Twenty-four hours (day 43) after the last dosing of all the groups, blood samples were collected.

\section{Collection of Blood Sample}

Blood samples were collected through the medial cantus into EDTA bottles for haematological and plasma biochemical studies. Before assays, the blood samples were centrifuge for 5 minutes using a bench-top centrifuge (Centromix) and the supernant plasma was then used for the determinations of the biochemical parameters.

\section{Determination of Haematological Parameters}

The red blood cells (RBC) and white blood cells (WBC) counts were determined by the improved Neubauer haemocytometer method. The haemoglobin $(\mathrm{Hb})$ concentration was determined according to Jain (1986), using the cyanomethaemoglobin method. The packed cell volume (PCV) was determined by the microhaematocrit method according to Dacie and Lewis (1991). Schilling method of differential lecukocyte count was used to determine the distribution of the various white blood cells (Mitruka and Rawnsley, 1977). Mean corpuscular volume $(\mathrm{MCV})$, mean corpuscular haemoglobin $(\mathrm{MCH})$ and mean corpuscular haemoglobin concentration (MCHC) were computed according to Jain (1986).

\section{Determination of Plasma Biochemical Parameters}

The total protein concentration was determined using the Bivret method (Reinhold, 1953) and the albumin concentration by the method of Doumas et al. (1971). The globulin concentration was calculated by subtracting the albumin concentration from the total protein concentration. Activities of plasma alanine transaminase (ALT) and aspartate transaminase (AST) were determined according to the method of Duncan (1994). All the above parameter were determined in the plasma using the Randox kits.

\section{Statistical Analysis}

The mean and standard error of mean (S.E.M.) were calculated for all values. Comparison between the control and experimental groups was done using one-way analysis of variance (ANOVA) with Duncan's Multiple Range Test. Differences were considered statistically significant at $\mathrm{p}<0.05$.

\section{Results}

Treatment of rats for 42 days with Bacchus, Chelsea and Rose-Daniel caused significant $(\mathrm{p}<0.05)$ increase in eosinophil values relative to the control, while Bacchus caused significant $(p<0.05)$ increase in monocyte value relative to the control. The administration of all the alcoholic beverages to the rats caused nonsignificant $(p>0.05)$ changes in platelet, total white blood cell (TWBC) and red blood cell (RBC) counts and some indices relating is it ( $\mathrm{Hb}, \mathrm{PCV}, \mathrm{MCV}, \mathrm{MCHC})$ when compared with their controls. Treatment of rats with all the alcoholic beverages (except Gulder and Rose-Daniel) caused significant $(\mathrm{p}<0.05)$ increase in $\mathrm{MCH}$ values, while Guiness caused significant $(\mathrm{p}<0.05)$ decrease and increase in neutrophil and lymphocyte values respectively relative $t$ the control.

Table 1:Effect of 42 days treatment with $10 \mathrm{ml} / \mathrm{kg} \mathrm{BW}$ of alcoholic beverages on haematogical parameters $(\mathbf{n}=5, * \mathbf{p}<0.05)$

\begin{tabular}{|l|l|l|l|l|l|l|}
\hline \multicolumn{1}{|c|}{ Parameters } & \multicolumn{1}{c|}{ Control } & \multicolumn{1}{c|}{ Bacchus } & \multicolumn{1}{c|}{ Chelsea } & \multicolumn{1}{c|}{ Gulder } & \multicolumn{1}{c|}{ Guiness } & Rose- Daniel \\
\hline $\mathrm{PCV}(\%)$ & $31.00 \pm 0.55$ & $31.00 \pm 2.00$ & $32.20 \pm 2.46$ & $35.80 \pm 1.24$ & $30.20 \pm 2.48$ & $35.80 \pm 0.66$ \\
\hline $\mathrm{Hb}(\mathrm{g} / \mathrm{dl})$ & $9.98 \pm 0.17$ & $10.20 \pm 0.73$ & $11.40 \pm 0.80$ & $11.60 \pm 0.42$ & $10.00 \pm 0.76$ & $11.70 \pm 0.22$ \\
\hline $\mathrm{RBC}\left(\mathrm{x} 10^{6} \mu \mathrm{l}\right)$ & $5.33 \pm 0.07$ & $5.16 \pm 0.45$ & $5.87 \pm 0.48$ & $5.82 \pm 0.24$ & $5.13 \pm 0.42$ & $5.76 \pm 0.16$ \\
\hline $\mathrm{MCV}(\mathrm{FL})$ & $58.20 \pm 1.49$ & $60.80 \pm 2.45$ & $58.50 \pm 0.93$ & $61.70 \pm 1.97$ & $58.90 \pm 0.49$ & $62.40 \pm 1.95$ \\
\hline $\mathrm{MCHC}(\mathrm{g} / \mathrm{dl})$ & $18.70 \pm 0.46$ & $20.00 \pm 0.80$ & $19.50 \pm 0.34$ & $20.00 \pm 0.66$ & $19.60 \pm 0.41$ & $20.40 \pm 0.68$ \\
\hline $\mathrm{MCH}(\mathrm{pg})$ & $32.20 \pm 0.06$ & $33.00 \pm 0.24^{*}$ & $33.20 \pm 0.14 *$ & $32.40 \pm 0.09$ & $33.20 \pm 0.45^{*}$ & $32.70 \pm 0.10$ \\
\hline $\mathrm{TWBC}\left(\mathrm{x} 10^{3} / \mu \mathrm{L}\right)$ & $11.00 \pm 2.72$ & $9.03 \pm 2.72$ & $7.49 \pm 0.64$ & $6.86 \pm 0.51$ & $9.22 \pm 0.70$ & $7.05 \pm 0.71$ \\
\hline Platelets $\left(\mathrm{x} 10^{5} / \mu \mathrm{L}\right)$ & $1.30 \pm 0.12$ & $1.30 \pm 0.10$ & $1.40 \pm 0.11$ & $1.30 \pm 0.18$ & $1.50 \pm 0.20$ & $1.20 \pm 0.09$ \\
\hline Neutrophils $(\%)$ & $50.00 \pm 4.32$ & $41.60 \pm 4.18$ & $38.80 \pm 5.91$ & $48.80 \pm 2.60$ & $32.60 \pm 31.6^{*}$ & $39.20 \pm 6.72$ \\
\hline
\end{tabular}


Effects Of Some Alcoholic Beverages On Haematological And Plasma Biochemical Parameters In

\begin{tabular}{|l|l|l|l|l|l|l|}
\hline Lymphocytes (\%) & $47.60 \pm 4.27$ & $53.20 \pm 3.92$ & $57.20 \pm 5.38$ & $49.80 \pm 2.65$ & $64.40 \pm 2.84^{*}$ & $57.20 \pm 6.97$ \\
\hline Eosinophils (\%) & $0.80 \pm 0.20$ & $2.80 \pm 0.66^{*}$ & $2.20 \pm 0.20^{*}$ & $0.80 \pm 0.37$ & $1.20 \pm 0.39$ & $2.80 \pm 0.58^{*}$ \\
\hline Monocytes (\%) & $0.60 \pm 0.24$ & $2.40 \pm 0.68^{*}$ & $1.80 \pm 0.66$ & $1.80 \pm 0.37$ & $1.80 \pm 0.49$ & $1.00 \pm 0.00$ \\
\hline
\end{tabular}

Treatment of rats for 42 days with all the alcoholic beverages caused significant $(\mathrm{p}<0.05)$ increase in total protein level relative to the control, while Bacchus and Rose-Daniel caused significant $(\mathrm{p}<0.05)$ increase in albumin level relative to the control. The administration of all the alcoholic beverages to the rats caused nonsignificant $(p>0.05)$ changes in globulin level relative to the control. Treatment of rats with all the alcoholic beverages (except Rose-Daniel) caused significant $(p<0.05)$ increase in the activity of AST relative to the control, also all the alcoholic beverages (except Bacchus and Rose-Daniel) caused significant $(\mathrm{p}<0.05)$ increase in the activity of ALT relative to the control.

Table 2:Effect of 42 days treatment with $10 \mathrm{ml} / \mathrm{kg} \mathrm{BW}$ of alcoholic beverages on plasma biochemical parameters $(\mathbf{n}=\mathbf{5}, * \mathbf{p}<0.05)$.

\begin{tabular}{|l|l|l|l|l|l|l|}
\hline \multicolumn{1}{|c|}{ Parameters } & \multicolumn{1}{c|}{ Control } & \multicolumn{1}{c|}{ Bacchus } & \multicolumn{1}{c|}{ Chelsea } & \multicolumn{1}{c|}{ Gulder } & \multicolumn{1}{c|}{ Guiness } & Rose-Daniel \\
\hline Total protein $(\mathrm{gm} \%)$ & $4.32 \pm 0.12$ & $5.48 \pm 0.27^{*}$ & $5.16 \pm 0.40^{*}$ & $5.14 \pm 0.13^{*}$ & $5.32 \pm 0.27^{*}$ & $5.46 \pm 0.15^{*}$ \\
\hline Albumin $(\mathrm{gm} \%)$ & $1.30 \pm 0.09$ & $2.34 \pm 0.14^{*}$ & $1.78 \pm 0.15$ & $1.74 \pm 0.15$ & $1.84 \pm 0.24$ & $1.92 \pm 0.22^{*}$ \\
\hline Globaulin $(\mathrm{gm} \%)$ & $2.94 \pm 0.21$ & $3.16 \pm 0.12$ & $3.26 \pm 0.40$ & $3.40 \pm 0.20$ & $3.48 \pm 0.24$ & $3.54 \pm 0.14$ \\
\hline AST $(\mu / \mathrm{L})$ & $17.80 \pm 1.32$ & $23.20 \pm 1.43^{*}$ & $30.60 \pm 1.17^{*}$ & $28.40 \pm 1.25^{*}$ & $25.20 \pm 2.46^{*}$ & $19.60 \pm 1.50$ \\
\hline ALT $(\mu / \mathrm{L})$ & $13.00 \pm 1.14$ & $18.00 \pm 1.92$ & $23.20 \pm 2.54^{*}$ & $22.60 \pm 1.75^{*}$ & $20.20 \pm 1.53^{*}$ & $16.60 \pm 1.33$ \\
\hline
\end{tabular}

\section{Discussion}

The haematological study has shown that treatment of rats with all the alcoholic beverages caused nonsignificant changes on the RBC count and indices relating to it (Hb, PCV, MCV and MCHC), which could indicate that there were no destruction of matured $\mathrm{RBC}$ and no change in the rate of erythropoiesis. This could also indicate that the alcoholic beverages do not have the potential to stimulate erythropoietin release from the kidneys as well as being unable to effect changes in the oxygen-carrying capacity of blood and the amount of oxygen delivered to the tissues since $\mathrm{RBC}$ and $\mathrm{Hb}$ are known to be very important in transferring respiratory gases. Bacchus, Chelsea and Guiness caused significant increase in $\mathrm{MCH}$ values which could indicate the induction of macrocytic anaemia, since increased $\mathrm{MCH}$ values are known to be indicative of macrocytic anaemia. Similar report was given by Adedapo et al. (2007) in rats trated with P. amarus and C. anontifolius extracts. Guiness caused significant reduction in neutrophil value which probably indicates a reduction in the ability of the body to attack and destroy invading bacteria, viruses and other injurious agents (phagocytosis). Contrary report was given Yakubu et al. (2007) in rats trated with Fadogia agrestis extract. However, Guiness caused significant increase in hymphocyte value which suggests that the acquired immune response of the body has been enhanced. Similar report was given by Adewusi and Afolayan (2009) in rats treated with Pelargonium reniforme extract. Bacchus, Chelsea and Rose-Daniel caused significant increase in eosinophil values which probably indicate that the anti-allergic and anti-parasitic infectious responses of the body have been enhanced. Similar report was given by Biu et al (2009) in rats treated with aqueous Neem extract. Bacchus caused significant increase in monocyte value which probably indicates an enhancement in the phagocytic function of the blood. Similar report was given by Taiwo et al (2009) in rats treated with $P$. amarus extract.

All the alcoholic beverages caused significant increase in total protein levels which probably indicate that the buffering capacity of the blood and the body fluid balance have been enhanced and not compromised respectively. Similar report was given by Adewusi and Afolayan (2009) in rats treated with Pelargonium reniforme extract. Bacchus and Rose-Daniel caused significant increase in albumin levels which could indicate an increment in serum levels of metals, ions, fatty acids, amino acids, bilirubin and enzymes. Similar report was given by Adedapo et al. (2007) in rats treated with P. amarus and C. Anontifolius extracts. All the alcoholic beverages caused non-significant changes in globulin levels which could indicate that both the natural and acquired immune responses of the body have not been compromised. All the alcoholic beverages (except Bacchus and Rose-Daniel) caused significant increase in the activities of ALT which probably indicate induction of hepatic damage. All the alcoholic beverages (except Rose-Daniel) caused significant increase in the activities of AST which probably indicate the induction of tissue necrosis.

\section{References}

[1] Adedapo AA, Abatan MO, Olorunsogo OO (2007): Effects of some plants of the spurge family on haematological and biochemical parameters in rats. VETERINARSKI ARHIV 77 (1), 29 - 38.

[2] Adewusi EA, Afolayan AJ (2009): Safety evaluation of the extract from the roots of Pelargonium reniforme Curtis in male wistar rats. Afr. J. Pharm and Pharmacology, vol. 3(8): pp. $368-373$.

[3] Biu AA, Yusufu SD, Rabo JS (2009): Studies on the effects of aqueous leaf extracts of Neem Azadirachta indica on haematological parameters in chicken. African scientist Vol. 10 No 4 pp $189-192$. 
[4] Carlsson S et al (2003): Alcohol consumption and the incidence of type 2 diabetis: a 20-year follow-up of the Finish Twin Cohort Study. Diabetis care 26(10): 2785 - 2786.

[5] Dacie JV, Lewis SM (1991): Practical haematology, 7th edition ELBS with Churchill Livingston, England, pp 37-85.

[6] De Wood MA, Spores J, Mouser LT, Burroughs R, Golden MS, Lang HT (1980): Prevalence of total coronary occlusion during the early hours of transmural myocardial infarction. N.Engl. J. Med. 303: 897 - 902.

[7] Dees WL, Dissen GA, Hiney JK (2000): Alcohol ingestion inhibits the increased secretion of puberty-related hormones in the developing female Rhesus monkey. Endocrinology 141: 1325 - 1331

[8] Doumas BT, Watson W, Biggs HC (1971): Albumin standards and the measurement of serum albumin with bromocresol green. Clinica Chimica Acta 31, 87-96.

[9] Duncan JR, Praise KW, Mahaffey EA (1994): Veterinary Laboratory Medicine (Clinical Pathology) 3rd ed. Iowa State University Press, U.S.A.

[10] Froehlich JC (1993): Interactions between alcohol and the endogenous opoid system. National Institute on Alcohol Abuse and Alcoholism Research Monograph No 23. NIH Pub. No. 93 - 3533. Bethesda, MD: National Institutes of Health, pp. 21 - 35.

[11] Fuchs FD, Chambless LE, Whelton PK, Nieto FJ, Heiss G (2001): Alcohol consumption and the incidence of hypertension: the Atheroscleosis Risk in Communities Study. Hypertension 37: 1242 - 1250.

[12] Jain NC (1986): Schalm's Veterinary Haematology 4th ed. Lea and Fabiger, Philadelphia.

[13] Mitruka BM, Rawnsley H (1977): Clinical, biochemical and haematological references values in normal experimental animals. Masson Publishing USA Inc. Pp. 53-54.

[14] Reinhold JG (1953): Manual determination of serum total protein, albumin and globulin fractions by the Biuret method Standard Methods of Clinical Chemistry (Academic Press, New York).

[15] Singer MV, Leffmann C, Eysselein VE, Calden H, Goebell H (1987): Action of ethanol and some alcoholic beverages on gastric acid secretion and release of gastrin in humans. Gastroenterology. 93: $1247-1254$

[16] Straus R (1979): An historical perspective on the clinical uses of wine Vintage, August, 1979.

[17] Taiwo IA, Oboh BO, Francis - Garuba PN (2009): Haematological properties of aqueous extracts of Phyllantus amarus and Xylopia aethiopica in albino rats. Ethno - Med 3 (2): $99-103$.

[18] Yakubu MT, Akanji MA, Oladiji AT (2007): Haematological evaluation in male albino rats following chronic administration of aqueous extract of Fadogia agrestis stem. Pharmacog. Mag. 3:34-34. 